\title{
Perception of E-Learning among Physiotherapy Students
}

\author{
Keerthika Ranji ${ }^{1}$, Shweta S.D Phadke², Pranati Tilak ${ }^{3}$ \\ ${ }^{1}$ Associate Professor, ${ }^{2}$ Principal, ${ }^{3}$ Campus Director; \\ TMV’s Lokmanya Medical College of Physiotherapy, Kharghar, Navi Mumbai \\ Corresponding Author: Keerthika Ranji
}

DOI: https://doi.org/10.52403/ijshr.20220103

\begin{abstract}
The COVID-19 pandemic has brought about a sudden drastic change in the teaching learning patterns globally. Educational institutes have shifted from the traditional classroom teaching to virtual classrooms. This transition is the need of the hour. It requires technical up gradation as well as better communication skills because the teacher and student are only interacting through a virtual platform. There are many difficulties that both teacher and students face during online teaching learning process. In this study we have tried to understand the perception of physiotherapy students towards E Learning. From the data received and analysed it was concluded that the physiotherapy students prefer traditional classroom teaching as it helps develop better hands on skills.
\end{abstract}

Keywords: E-Learning, Physiotherapy Students, COVID-19 pandemic

\section{INTRODUCTION}

The world witnessed the outbreak of severe acute respiratory syndrome coronavirus 2 (SARS-CoV-2) recently. It has affected all the nations of the world and brought life to a standstill. The World Health Organization declared it as a pandemic on 11th March $2020^{(1)}$. In order to ensure the safety of their citizens several governments adopted measures such as social distancing, imposing travel restrictions and lockdown ${ }^{(2,3)}$. Though life came to a standstill educational institutions had to continue operations. This had a great impact on the education system in developing countries like India where the traditional system of education is predominant. The learners and teachers had to rapidly shift from face to face teaching learning to an online mode of education. Many considered this as a blessing in disguise. Several creative solutions emerged to facilitate the teaching learning process. The education sector in India was revamped and digitisation in the field of education took place with full potential as it was the need of the hour ${ }^{(4)}$.

E learning emerged as the new method of imparting education. It can be defined as the use of various technological tools that are either Web based, Web distributed or Web capable for the purposes of education ${ }^{(5)}$. There are multiple advantages of E learning. It allows students to acquire knowledge and skills without having to be physically present at universities. This also reduces the burden on the universities in terms of providing infrastructure and other necessities ${ }^{(6)}$. Though E learning has several advantages it also poses many challenges to both teachers and learners. They need to be updated with the technological advances. Students need to be self-motivated to read the study materials provided in the learning management system, participate in discussions, complete and upload assignments etc ${ }^{(7)}$. The coursework for Physiotherapy requires theoretical knowledge and hands on practical skills training. In the module of $\mathrm{E}$ learning the component of supervised 
practical skills development is compromised.

Our institute incorporated various techniques of teaching learning during the pandemic situation. As there was no standard protocol in existence to face such a situation, we conducted studies which will help in evidence based practice in order to ensure that our students attain quality education $^{(8,9,10,11)}$. Thus, this study was conducted to understand the perception of $\mathrm{E}$ learning among Physiotherapy students.

\section{METHODOLOGY}

The study design was Survey. An online survey was conducted using a Google form. The Google form was circulated among students enrolled in undergraduate and post graduate Physiotherapy programs in Maharashtra. An informed consent was obtained from the participants before they started answering the questions in the form. The form consisted of questions pertaining to several aspects of the new online teaching learning mode. We included questions to obtain data about the students' perception to E Learning based on factors such as availability of technical requirements, comfort in using gadgets for prolonged hours, ease of understanding the lecture content, distractions during online classes and advantages and disadvantages of $\mathrm{E}$ learning. The data thus obtained was statistically analysed

\section{Data Analysis}

The data obtained from the duly filled questionnaires was statistically analysed. Total numbers of responses received were203.

The results of the study have revealed several aspects of perception from the viewpoint of Physiotherapy students. Majority of the students were in the age group of 18 to 21 years. Of the total number of responses received; majority (28.6\%) were from third year Bachelor of Physiotherapy students. The respondents have shown clear preferences in certain domains while marginal difference of choice exists in other domains. Most of the participants have opted for virtual classrooms and Zoom as the preferred platform for E learning. Many students had taken online courses in the past and majority of them were equipped with the technical paraphernalia for E learning. Despite this, greater proportion of students were uncomfortable spending long hours using devices. Also, maximum students have shown a non-preference for E learning. The only major advantage of E learning that the students perceived was the ability to remain in a comfortable environment while learning via the online mode. The major difficulty encountered by the students was understanding practical demonstrations.

Preference of Mode of E Learning

203 responses

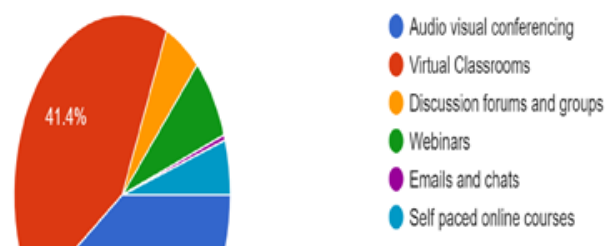

Preference of Online Platform for Elearning

203 responses

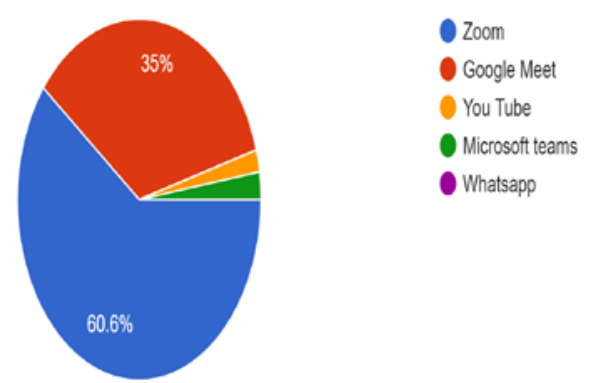

Taken online courses in the past

203 responses

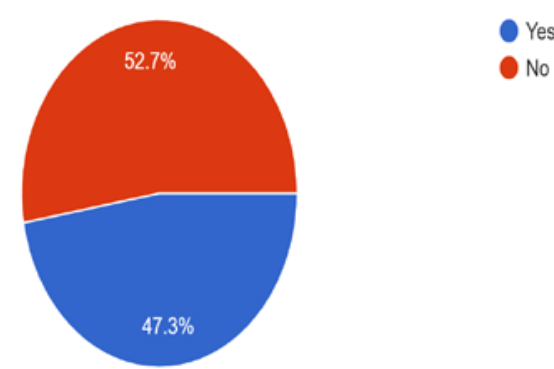


Possess all technology, software and applications required 203 responses

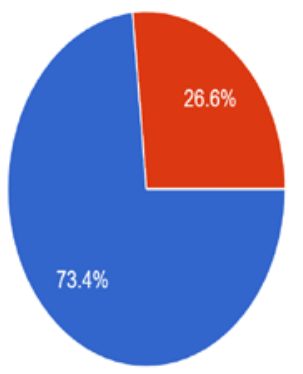

Are you comfortable spending several hours on laptop, mobile phone or tablet 203 responses

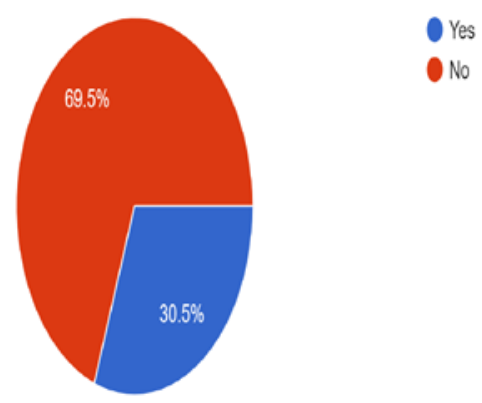

Do you enjoy E- learning

203 responses

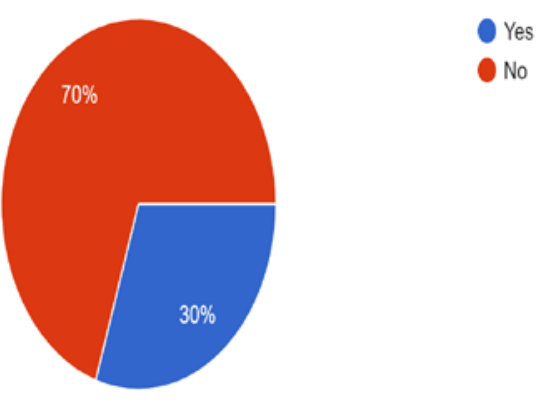

Do you prefer E- learning compared to classroom learning 203 responses

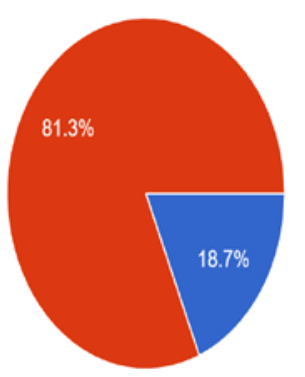

\section{Advantages of $E$ learning}

203 responses

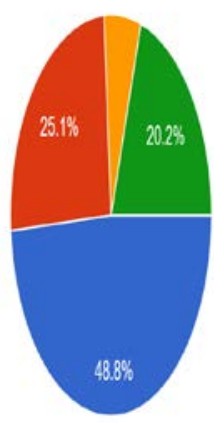

Being ina comitorable enrironment:

Time saing

Costefective

Reperability o c content

\section{Disadvantages of $E$ learning}

203 ressonses

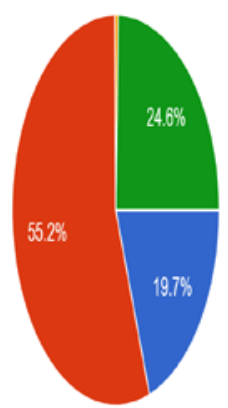

1 Inability to focus or concentrate

10 Dificuly in understanding practical demonstrations

0 Language barier

0 Mutiple sources of ofistration

In which area is your college located

203 responses

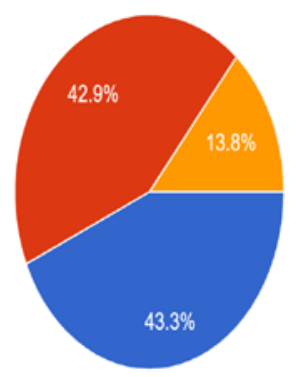

- City

- Town

Village

In which area is your home located

203 responses

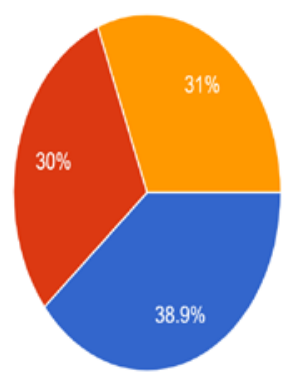

- City

0 Town

Village 


\section{DISCUSSION}

The online mode of teaching learning is novel in the case of medical education. Besides, the transition from offline to an online mode was sudden. As students and teachers were coping up with this unexpected change, they hardly had enough time to acclimatize themselves to this new mode. Also not all were equipped with the technical paraphernalia required to effectively deliver the content via online mode.

Thus we conducted this study in order to understand the perception of physiotherapy students towards E learning. The results of the study has brought forth several important revelations the implications of which can be put to use for the enhancement of knowledge deliverance.

In order to facilitate effective online learning it is important to ensure social and cognitive presence as well ${ }^{(12,13)}$. This explains the preference of greater proportion of students for virtual classrooms and audio visual conferencing. A common difficulty experienced by students and teachers in the online mode is the lack of social presence (12). The platform of Zoom is extremely user friendly and allows social presence which is the ability to express themselves socially and emotionally as real human beings. Thus students prefer the Zoom platform for online classes.

As physiotherapy is a health science course, the students need to have better hands on practical skills training which will enable them to apply diagnostic tests and therapeutic manoeuvres effectively on patients $^{(14)}$. The lack of human touch and interaction also makes the course module uninteresting, so they do not enjoy $\mathrm{E}$ learning. Thus, the participants of this study have demonstrated a non preference for $\mathrm{E}$ learning.

Though the students have adopted to the online mode, they are not as gadget friendly and not comfortable spending long hours on mobile phones, tablets or computers They reported difficulties with installation and use of the supporting software as they lacked advanced computer skills (15). However, the transition from traditional teaching learning to an interface based system is an evolving practice. Several mobile and computer applications are being developed making online learning more user friendly. Another disadvantage of E learning identified in our study was that the students had to motivate themselves and incorporate time management strategies in order to ensure effective learning. The primary cause for this could be the presence of multiple sources of distraction in the environment from where they attend their online classes ${ }^{(16)}$.

E-learning also has certain advantages as it is time saving, economical, offers repeatability of content and provides the students with flexibility and reduces their dependence on faculties. Students also felt that they could continue learning in their comfortable environment ${ }^{(6)}$.

As greater proportion of the participants of our study were located in cities and towns, they had good infrastructure, resources and internet connectivity. There is a scope for similar studies to be conducted in rural areas as well.

\section{CONLUSION}

Persistence of the current pandemic situation along with the restrictions imposed by government bodies will encourage the online mode of teaching and learning. Though it has several advantages, the students studying the subject of Physiotherapy have shown a clear preference for traditional mode of learning. Thus, we can employ blended learning methods to overcome the problems faced by the students in an online mode of learning.

\section{Suggestions for Further Study}

Similar studies can be conducted in students pursuing other faculties as well. Researchers can also study the problems encountered by students residing in rural areas as it will help development of technology to cater to their needs. 
Acknowledgement: None

\section{Conflict of Interest: None}

\section{Source of Funding: None}

\section{REFERENCES}

1. Ibrahim NK. Epidemiologic surveillance for controlling Covid-19 pandemic: types, challenges and implications. J Infect Public Health 2020;13(11):1630-8.

2. Cucinotta, D.; Vanelli, M. WHO Declares COVID-19 a Pandemic. Acta BioMed. 2020, 91, 157-160.

3. Sahu, P. Closure of Universities Due to Coronavirus Disease 2019 (COVID-19): Impact on Education and Mental Health of Students and Academic Staff. Cureus 2020, 12.

4. T. Muthuprasad, S. Aiswarya, K.S. Aditya, Girish K. Jha, Students' perception and preference for online education in India during COVID-19 pandemic, Social Sciences \& Humanities Open, Volume 3, Issue 1,2021,100101,ISSN 2590-2911.

5. Nichols, M. (2003). A theory for eLearning. Educational Technology \& Society, 6(2), 110.

6. Megha Sheth, Priyasingh Rangey, Srishti Sharma. Perception of e-learning among physiotherapy students during the covid-19 pandemic. Int. J. Adv. Res. 8(08), 193-201

7. Cantoni V, Cellaro M, Porta M. Perspectives and challenges in e-learning: towards natural interaction and paradigm. Journal of Visual Languages \& Computing. 2004; 15(5): 333-345.

8. P Tilak, M Deshmukh, S Phadake, Dr. Sabina S.K Hakim,A survey on online examination during COVID 19 pandemic: Perception of Management Students, Mukt Shabd Journal, 2020,9 (VIII), 285-290.

9. Dr. Sabina S.K Hakim, Dr. Shweta S Phadke, DP Tilak, DM Deshmukh, Online Examination during Covid-19 Pandemic-
Physiotherapy Student's Perspective, International Research Journal of Engineering and Technology (IRJET), 2020, 7(08), 2633-2637.

10. DP Grover, DSSD Phadke, DP Tilak, Efficacy of flipped classroom teaching on the cognitive domain in second year Physiotherapy students, Medical Journal of Dr. DY Patil Vidyapeeth, 2021

11. Shweta SD Phadke, SSK Hakim, P Tilak, Moving To Online: The Transition Seen In Physiotherapy Education During Covid 19 Pandemic. Turkish Journal Of Physiotherapy And Rehabilitation, 2021, (3),6683-6687.

12. Garrison, D.R. Online community of inquiry review: Social, cognitive, and teaching presence issues. Online Learn. 2019, 11, 59.

13. Garrison, D.R.; Anderson, T.; Archer, W. The first decade of the community of inquiry framework: A retrospective. Internet High. Educ. 2010, 13, 5-9.

14. Warneck E, Pearson S. Medical students' perceptions of using e-learning to enhance acquisition of consulting skills. Australasian Medical Journal. 2006; 4(6):300-307

15. Linjawi AI, Alfadda LS. Students' perception, attitudes, and readiness toward online learning in dental education in Saudi Arabia: a cohort study. Adv Med Educ Pract. 2018; 9: 855-863

16. Bertea P. Measuring students' attitude towards e-learning. A case study. The fifth International scientific conference: Elearning and Software for education. April 2019.

How to cite this article: Keerthika Ranji, Shweta S.D Phadke, Pranati Tilak. Perception of elearning among physiotherapy students. International Journal of Science \& Healthcare Research. 2022; 7(1): 12-16. DOI: https:// doi.org/10.52403/ijshr.20220103 